\title{
VALIDATION OF S-LOMS AND COMPARISON BETWEEN HONG KONG AND SINGAPORE OF STUDENT DEVELOPMENTAL OUTCOMES AFTER SERVICE-LEARNING EXPERIENCE
}

\author{
Ka Hing Lau, \& Robin Stanley Snell
}

\section{Abstract}

Service-learning was introduced to tertiary education in Asia more than a decade ago. However, there has been little prior Asia-based research across different jurisdictions comparing student developmental outcomes arising from service-learning. We report two studies that validated the Service-Learning Outcomes Measurement Scale (S-LOMS) by comparing its scores obtained from Hong Kong and Singapore samples. Study 1 employed confirmatory factor analysis, and the results showed that S-LOMS is a reliable measurement instrument for both jurisdictions. Study 2 compared the developmental outcomes arising from servicelearning for Hong Kong and Singapore students across the 11 domains of S-LOMS. Investigation of the pretest data (baseline) indicated significantly higher scores for Singapore students on seven domains, which may have reflected greater prior exposure to community service, as compared with the Hong Kong students. Comparisons of pretest and posttest scores through paired sample t-tests indicated that service-learning had significantly greater developmental outcomes in five domains for Hong Kong students as compared with Singapore students. While there were no significant improvements for Singapore students in caring and respect, sense of social responsibility, and commitment to self-improvement, Hong Kong students perceived themselves as having significantly improved in all domains. Possible reasons for the Study 2 results are discussed.

\section{An Overview of Service-Learning}

Service-learning originated in the United States around 50 years ago and has subsequently been adopted across the world, entering Asia during the last two decades (Ma, 2018b; Shumer et al., 2017; Xing \& Ma, 2010). This experiential pedagogy seeks to engage students in applying academic knowledge and skills to tackle issues arising while undertaking community service, aided by reflection of students on how the service experience connects to the curriculum (Jacoby, 1996). 
Service-learning, whether undertaken in conjunction with academic courses (Eyler \& Giles, 1999; Snell \& Lau, 2020) or with academically contextualized work internships (Snell et al., 2019; Wong et al., 2021), has been found to have significant developmental benefits for students. In terms of community impact, students undertaking service-learning can augment the services provided by regular employees in community organizations and inspire service improvements (Lau et al., 2020).

Recognition of the potential benefits of service-learning for students and the community appears to have dovetailed with a movement across Asia to induce universities to invest resources in transferring knowledge to the community and in cultivating whole person development for students, including moral development and civic orientation. In 2006, Lingnan University (LU) was the first in Hong Kong to establish an Office of ServiceLearning (OSL) with the mission of institutionalizing service-learning across the undergraduate curriculum and of supporting faculty in implementing service-learning. About a decade later, service-learning was made a graduation requirement both at LU (Lau \& Snell, 2020b) and at The Hong Kong Polytechnic University (HKPU) (Shek et al., 2015). Universities in other Asian jurisdictions, such as Taiwan, Singapore, South Korea, and Japan, have also established units to support service-learning programs (Xing \& Ma, 2010).

The rise of service-learning in Asia has been rapid, but as yet there have been very few cross-jurisdictional research studies in Asia on the developmental outcomes for students. One reason for this relative dearth of research has been the lack of a relevant measurement instrument with established reliability and validity (Snell $\&$ Lau, 2020). Reliance on qualitative methods or on imported measurement scales from the West has tended to limit the generalizability of any research findings. The Service-Learning Outcomes Measurement Scale (S-LOMS) (Snell \& Lau, 2020) has therefore been developed as a standardized instrument, designed to measure developmental domains that reflect the developmental aims of service-learning programs found in the universities across Hong Kong.

As described by Snell and Lau (2020), S-LOMS comprises four overarching developmental categories with 11 developmental domains. The first category, knowledge application, comprises a single cognominal domain (four items). The second category, personal and professional skills, comprises creative problem-solving skills (eight items), relationship and team skills (eight items), self-reflection skills (four items), and critical thinking skills (three items). The third category, civic orientation and engagement, comprises community commitment and understanding (eight items), caring and respect (seven items), and sense of social responsibility (three items). The fourth category, self-awareness, comprises self-efficacy (four items), self-understanding (four items), and commitment to self-improvement (three items).

According to Snell and Lau (2020), while the construction process for S-LOMS was guided by prior international literature, close attention was paid to the three characteristics of the localization of service-learning in Hong Kong. The first is an emphasis on the development of professional skills, reflecting the relatively instrumental ethos of education in Hong Kong. A tendency for the general public in Hong Kong to regard education as a pathway to upward social mobility may have inclined service-learning programs toward vocationally oriented skill development. The second is an emphasis on self-reflection and self-improvement as means for the development of self-understanding and self-efficacy, reflecting the influence of Confucian ideals and values 
concerning self-cultivation. Third, as compared with Western counterparts, service-learning programs in Hong Kong appear to have adopted a relatively depoliticized approach to civic engagement in emphasizing civic duty rather than commitment to the furtherance of social justice in a democratic society.

S-LOMS has been piloted in three Hong Kong-based universities, and a partial version has been piloted in a fourth. Validation studies have demonstrated that S-LOMS has sufficient content, construct, test-retest, and criterion validity in Hong Kong, as well as good internal consistency in terms of Cronbach's alpha (see Lau \& Snell, 2020a, 2020c, 2021; Snell \& Lau, 2020).

\section{The Current Research}

Besides Hong Kong, other parts of Asia, such as Singapore, Korea, and Japan, have also been influenced by Confucianism $(\mathrm{Tu}, 1996)$. It is possible that this common root has given rise to similarities that are expressed in relatively similar aims for and approaches to service-learning. It was also considered possible that S-LOMS could also be a suitable instrument for measuring the developmental outcomes of service-learning in Asian jurisdictions beyond Hong Kong.

If so, S-LOMS might potentially afford a common platform for academics in different Asian jurisdictions to undertake comparison studies of the developmental outcomes of service-learning. As an initial exploratory step toward this, we compared the student developmental outcomes arising from service-learning in Hong Kong and Singapore. Both jurisdictions are international in terms of institutions but are also strongly influenced by Confucian values, and ethnic Chinese people constitute the majority of their populations. There are also similarities in terms of economic development and educational policies, as analyzed below.

The first aim of the current research was to validate S-LOMS across the two jurisdictions in Study 1, by testing whether the same underlying factor structure and internal consistency emerge from samples of students recruited from tertiary education institutions in Hong Kong and Singapore. The second aim of the research was addressed in Study 2, which compared the developmental outcomes of service-learning for the two samples of students by examining differences in terms of pretest and posttest scores. Study 2 thus served as an exploratory illustration of how S-LOMS can be used in comparative service-learning research.

\section{Comparing Societal Contexts and Educational Policies in Hong Kong and Singapore}

As institutional and societal venues for tertiary education, Hong Kong and Singapore have many similarities. Geographically, they are both small territories that are reliant upon human resources, such that education has been of great importance to their development. Moreover, both places have a high proportion of ethnic Chi- 
nese. The corresponding figures are 92\% in Hong Kong (Census and Statistics Department of the HKSAR Government, 2020) and 76\% in Singapore (Department of Statistics, Singapore, 2020). Both jurisdictions have accordingly been strongly influenced by Confucianism. As described by Gabrenya and Hwang (1996), Confucianism "is a thoroughly secular, this-world system . . . to allow . . . a modicum of harmony in the cool embrace of inescapable hierarchy ... in which power differentials and responsibilities are prescribed ... characterized by conformity to the role expectations" (p. 310). Hofstede (1983) categorized the organizational values in Hong Kong and Singapore as preferring high power distance, high masculinity, low uncertainty avoidance, and low individualism. These characteristics are compatible with Confucian values.

Two additional themes in Confucianism have exerted strong influences on the curriculum of tertiary education. The first is the importance of self-cultivation and the cultivation of moral responsibility through constant self-reflection and self-examination (Cheng, 2004; Tu, 1971). The second is a traditional mindset in Chinese societies of regarding education primarily as an opportunity to progress to high status careers (Marginson, 2011; Shek \& Chan, 2013). This tends to be expressed as an instrumental orientation toward educational policy-making.

Accordingly, the educational policies of Hong Kong and Singapore have many similarities. For Singapore, a major objective of education has been to provide enough educated and skilled labor to meet industrial needs for economic competitiveness (Tan, 2007; Wong, 1988). The Singapore government has emphasized the need to train students to become lifelong learners, to acquire creative and critical thinking ability, and to be well versed in information technology. We shall mention three examples. The first is the Thinking Schools, Learning Nation (TSLN) vision, which aspired to reform schools, through curriculum redesign, to become powerhouses for developing students into thoughtful and committed citizens primed to engage in lifelong learning (Gopinathan, 2007). The second is the SkillsFuture movement, which was introduced by the Singapore government with the intention of providing young people with key skills relevant to the future in 2014 (Tan, 2017; Yorozu, 2017). The third is the review of school curricula, undertaken by the Curriculum 2015 Committee in 2008. This review sought to steer primary and secondary schools toward emphasizing 21st century skills, including skills of thinking, communication, collaboration, and management, under a broad-based and holistic curriculum so as to help students to excel in future global economic competition (Lee \& Gopinathan, 2018).

Hong Kong was greatly impacted by the open-door policy initiated by mainland China, which gave rise to much cross-border investment in manufacturing, especially after the early 1990s. This steered Hong Kong away from being a manufacturing and trading center and toward being a knowledge-based economy, offering financial, business, and other services and requiring education to provide higher levels of skills and knowledge to its future labor force (Morris \& Adamson, 2010). A report released by the Hong Kong Special Administrative Region (HKSAR) government in 2001 set out a vision of equipping students with 21st century skills and knowledge. These target domains included bilingual and numeric skills, communication skills, and competence in the use of information technology and critical thinking, along with becoming lifelong learners with whole-person development (Curriculum Development Council, 2001). We may thus observe similar instrumental purposes and designs for tertiary education across the two jurisdictions.

The philosophy of "education for the economy" appears to have manifest in both jurisdictions since the 1990s, 
especially through their educational reforms during the last 20 years, intended to address the challenges of globalization and the knowledge-based economy. Lee and Gopinathan (2018) provided an excellent review of the reforms in both jurisdictions, which they summarized as three common directions. The first has involved seeking to increase economic competitiveness by emphasizing the development of students' thinking and knowledge inquiry skills and their lifelong learning habits. The second has entailed nourishing and deepening citizenship identity under the framework of moral and civic education. The third has entailed seeking to reduce inequalities of educational opportunity by building more diversified schooling systems. The main difference between the two jurisdictions in terms of educational policies and systems concerns the extent to which national education has been integrated into civic education. As pointed out by Lee and Gopinathan (2018), national education has been well received in Singapore. However, in Hong Kong national education has faced strong resistance, and there has been considerable disagreement about whether, and how, citizenship and national education should be integrated and implemented, and stalemate has persisted.

Notwithstanding the key difference mentioned above, Hong Kong and Singapore have tended to adopt similar approaches to civic education. Since achieving independence, Singapore has operated as a semi-authoritarian state, practicing top-down governance (Bell, 1995; George, 2007; Turner, 2014; Woo, 2019), underpinned by a neo-Confucianism philosophy. Civic education in Singapore accordingly emphasizes forging national identity, enhancing social cohesion, and cultivating appropriate moral values and conduct (Gopinathan, 2007; Sim \& Print, 2005) rather than inculcating democratic principles and processes, which are given greater emphasis in the West (Sim \& Print, 2005).

Examples in Singapore include the Community Involvement Programme (CIP) launched by the Ministry of Education (MOE) in 1997. This required all primary and secondary students to fulfill a minimum quota of community engagement hours every year (HistorySG, 2020). The CIP was later replaced by Values in Action (VIA) in 2012, which has had a similar goal of developing students into socially responsible citizens (Choo et al., 2019). Moreover, the Singapore government has further integrated national education with civic education under a Character and Citizenship Education (CCE) curriculum, associated with the education reform in the early 2010s that involved all levels of pre-university education (Lee \& Gopinathan, 2018). We will explain later how the development of service-learning in Singapore has been closely aligned with these various measures.

Hong Kong has adopted an executive-led approach for public governance both before and after the 1997 transition of sovereignty (Cheung, 2007). In contemporary Hong Kong, government officials have been seeking to reinforce the identity of Hong Kong people as subjects within a depoliticized city, focusing on financial and business activities on Chinese soil (for details, see Leung \& Ng, 2014). To that end, civic education has largely de-emphasized politics. The educational policy reviews conducted during the first decade of the new millennium, followed by educational reforms, emphasized whole-person development and social responsibility rather than democratic engagement (Snell \& Lau, 2020). Although in 2011, the HKSAR government tried to propose a new Moral and National Education (MNE) scheme, the associated proposals were not well received by stakeholders and resulted in its suspension (Lee \& Gopinathan, 2018).

Thus, in both Hong Kong and Singapore, topics relating to political systems and democracy that are normally 
addressed under Western civic education are barely touched upon. Accordingly, the educational aims of servicelearning in both jurisdictions emphasize how the individual can learn to fit into groups and organizations and contribute to society rather than learning about how to challenge institutions and bring about change. The aims of service-learning in both jurisdictions focus more on moral and personal development, empathy and caring, respecting people from different backgrounds, and community service. Correspondingly, less attention is paid to the advocacy and furtherance of democratic values and social justice.

In summary, we have identified four common characteristics of tertiary education policies in Singapore and Hong Kong. First, education is framed as an instrumental tool to sustain economic growth. Second, there is an emphasis on technological knowledge, and on skills of critical thinking and problem-solving, in order to remain competitive within a global knowledge economy. Third, there is recognition of the need to cultivate students' motivation and ability to engage in lifelong learning. Fourth, civic education is regarded as a priority but is designed and delivered in a depoliticized mode.

\section{Service-Learning in Hong Kong and Singapore}

Our above analysis has identified many similarities in the institutional contexts for the localization of servicelearning in Hong Kong and Singapore. We shall now review the purposes and design of service-learning in the two jurisdictions. Service-learning in Singapore was foreshadowed in 2000 as a pedagogy adopted by the MOE, based on the CIP, which required all students at primary to pre-university levels to serve the community for a stipulated number of hours each year. The CIP was then renamed as VIA ${ }^{1}$ by focusing on values inculcation through community involvement, and service-learning emerged as one approach to VIA, as recommended by the MOE. Service-learning in Singapore has thus been framed as an integral part of the state's civic education policy. While seeking to promote an appreciation for good governance, a major emphasis has been on building social cohesion and inculcating civic responsibility in students, along with complementary personal qualities and skills, such as leadership, personal growth, interpersonal development, and project management (Chang \& Yap, 2017; Ma, 2018a).

At the primary and secondary educational levels in Singapore, contemporary service-learning is mandated under the framework of the VIA program, which seeks to develop students into socially responsible citizens by contributing to the community and reflecting on the related experiences (Ma, 2018a; MOE, 2020). In addition, many tertiary educational institutions have voluntarily adopted service-learning. Among the six governmentfunded universities, two have made service-learning a graduation requirement for all students. Singapore Management University (which required at least 80 service hours) adopted this policy in 2000, followed by the Singapore University of Social Sciences in 2014. In addition, the National Institute of Education (part of Nanyang Technological University) introduced a compulsory service-learning requirement for all pre-service student teachers in 2005. The National University of Singapore first introduced courses with service-learning elements

1. Contemporary service-learning de-emphasizes the mandatory service hours requirement and adopts a more flexible approach in order to better meet real community needs and promote student reflection. 
in 2001. Among the five polytechnics in Singapore, Republic Polytechnic (RP) adopted service-learning in 2007, and Ngee Ann Polytechnic did so in 2016 (Chang \& Yap, 2017; Choo, et al., 2019).

In Hong Kong, service-learning was first introduced by the Hong Kong government at the primary and secondary education levels in the 1980s (Education Bureau of the HKSAR Government, 2020). Service-learning was subsequently recommended as a strategy for civic education under the early 21st-century primary and secondary education reforms (Curriculum Development Council, 2001) but to date has not been made compulsory for the students. Currently, service-learning organized by primary and secondary schools is typically designed by schoolteachers and is embedded in extra-curricular activities, community service, and overseas exchange.

The local roots of service-learning at the tertiary level in Hong Kong can be traced back to 1995, when Chung Chi College of The Chinese University of Hong Kong adopted a volunteering or social services concept. LU introduced what we would recognize today as service-learning in 2004 and established Hong Kong's first Office of Service-Learning in 2006. Other local universities subsequently followed suit (Ma, 2018b), such that all eight government universities in Hong Kong and at least one of the three private universities (i.e., The Hang Seng University of Hong Kong) (HSUHK) now adopt service-learning. Among them, LU and HKPU have made completion of credit-bearing service-learning-based courses a graduation requirement for undergraduates (Lau \& Snell, 2020b; Shek et al., 2015).

Inter-jurisdictional comparisons indicate two broad differences regarding service-learning policies. First, the Singapore government has stipulated that community service, which we may regard as a precursor of servicelearning, should be mandatory for all primary and secondary students, whereas the Hong Kong government has not done so. Second, Singapore has emphasized community service as a key means for strengthening national identity, whereas, again, Hong Kong has not done so, reflecting unresolved issues related to the 1997 transition of sovereignty to China.

Comparison of the institutionalization of service-learning in Hong Kong and Singapore indicates four broad similarities across the two jurisdictions. First, the adoption of service-learning at primary and secondary levels has been intended to integrate community service with civic education. Second, service-learning has been widely adopted at the tertiary level, but there is no common stance across institutions about making it mandatory for all undergraduate students. Third, in both jurisdictions, the goals of service-learning align with broader educational goals that emphasize economic instrumentality, reflected in targeting the development of vocational skills, along with moral development rather than appreciation of and commitment to democratic values.

The fourth similarity is that in both jurisdictions, engagement in service-learning is relatively depoliticized. For example, students may learn to advocate handwashing and mask-wearing to the general public as a means for preventing COVID-19. It is, however, unlikely that they would be encouraged to pursue projects that challenge government policy by advocating the re-housing of migrant workers in sufficiently spacious premises that allow for social distancing and that lobby governments to more generally improve the rights and status of migrant workers.

The depoliticized characteristics of Hong Kong-based service-learning have been further analyzed by Snell and Lau (2020), and similar patterns can be observed in literature on Singaporean service-learning. For example, 
Tan (2009) identified four differences between service-learning practices in Singapore and in the United States. First, there is a weaker presence of community service in Singapore's universities, reflecting an emphasis on training to meet the requirements of the economy. Second, there is weaker orientation toward and awareness of social justice in Singapore. Third, despite the Singapore government's claims to promote synergy through cultural diversity, service-learning tends not to address this sensitive agenda. Fourth, Singapore students prefer to avoid politicizing their own service-learning activities. A review by Chang and Yap (2017) similarly reflects that although service-learning in Singapore emphasizes community engagement, the themes that are typically espoused in the West, such as participatory democracy, social justice, and social change, are absent.

In summary, we believe that Hong Kong and Singapore share many similarities in terms of societal contexts, salient educational policies, and goals for civic education and service-learning. Accordingly, we considered that S-LOMS, which was designed to assess outcomes across 11 developmental domains for Hong Kong students undertaking relatively depoliticized forms of service-learning (Snell \& Lau, 2020), would also be a suitable instrument for use to measure the developmental outcomes of service-learning in Singapore.

Further justifications for positing that S-LOMS is applicable in and salient for Singapore as well as Hong Kong are given next, with reference to the four overarching categories, under which the 11 developmental domains in S-LOMS are subsumed. First, we consider that knowledge application, that is, the extent to which students can apply subject knowledge to practical, real-life situations and problems, is universally regarded as a major goal of service-learning.

Second, personal and professional skills, which include soft skills that cannot be easily learned from lectures and books alone, are highly salient in the context of education for the economy, a philosophy that has been strongly embraced in both Hong Kong and Singapore. We have noted above that education for the economy emphasizes the need for students to become creative problem solvers and critical thinkers, with good project management skills and interpersonal competence. In S-LOMS, the overarching category of personal and professional skills also includes the domain of self-reflection skills, which are highly emphasized in service-learning in both jurisdictions (Chang \& Yap, 2017; Ma et al., 2019).

Third, civic orientation and engagement, comprising the developmental domains of community commitment and understanding, caring and respect, and sense of social responsibility, are highly congruent with the adoption of service-learning as a vehicle for civic education in both jurisdictions, as described above. Notably, a subscale measuring civic outcomes, used in a prior study of developmental outcomes of service-learning in Singapore by Choo et al. (2019), includes similar items such as "I am aware of what can be done to meet the important needs in the community" and "I plan to find time or a way to make a positive difference in the community." Choo et al. also provided an illustration from their qualitative data of "learning to take perspective of community partner and being tactful.”

Fourth, awareness of one's own strengths and weaknesses in terms of abilities and personal attributes is highly salient for education policies in both jurisdictions. This comprises the developmental domains of commitment to self-improvement, self-understanding, and self-efficacy. Qualitative data in the above-mentioned study by Choo et al. (2019) have suggested the salience of this set of domains in Singapore, with quoted examples of "per- 
severance," "recognising personal weakness," "realising undesirable traits in self and changed," "realising that I can," and "realising that I am more capable than I thought." As noted above, aspiration to realize Confucian values, oriented as they are to moral self-cultivation and to ongoing self-reflection and self-examination (Cheng, 2004; Tu, 1971), continues to guide educational policy-making in both jurisdictions. This is manifest, for example, in espousals of the importance of developing students into citizens with lifelong learning habits.

\section{Objectives of the Two Studies}

In Study 1, we sought to establish whether the 11 developmental domains as measured by S-LOMS share a similar underlying dimensionality and factor structure when used with Hong Kong and Singapore samples, as demonstrated by confirmatory factor analysis. In Study 2, we tested for significant differences between findings obtained from Hong Kong and Singapore, in terms of the pattern of pretest and posttest scores across the 11 domains. We anticipated that the many cross-jurisdictional similarities in service-learning policies would be forces for similarity in the patterns of scores obtained from S-LOMS. However, we also anticipated that we might observe some differences in such patterns, reflecting differences in the service-learning policies adopted in the two jurisdictions as well as differences in sample composition and institution-specific service-learning program designs.

\section{Study 1}

\section{Methods}

Study 1 sought to confirm the validity and reliability of S-LOMS for samples across tertiary education students in Hong Kong and Singapore. We conducted confirmatory factor analysis (CFA) by first aggregating the two samples. Our design was that if the model fit well, it should survive a multi-sample analysis by comparing the model structure across the two samples.

\section{Participants E' Procedure}

For the Hong Kong sample, 655 students were recruited from local universities. Most of them came from LU $(n=609)$, followed by Hong Kong Baptist University (HKBU) $(n=38)$, The Education University of Hong Kong $(\mathrm{EdHK})(n=4)$, and HSUHK $(n=4)$. Data were available from another 268 students from HKPU but were not included in Study 1 because the students in question only answered 26 items from S-LOMS instead of the full scale, rendering their responses incomplete for the CFA. The students were invited to complete the 56-item S-LOMS before undertaking service-learning in academic year 2019/20. Regarding the demographics, $69.5 \%$ were female, and there was a mean age of 20.7 years. They came from various disciplines, including the arts (31.6\%), social sciences (22.4\%), business (42.9\%), and engineering/science (3.1\%). 
For the Singapore sample, 330 students were recruited from RP. As with their Hong Kong counterpart, they were asked to complete S-LOMS before they commenced their service-learning projects during the same period. Regarding demographics, $68.8 \%$ were female, and the mean age of the sample was 19.4 years. The students came from various disciplines, comprising the arts (1.2\%), social sciences (13.0\%), business (4.5\%), engineering/science (43.9\%), and health care (37.3\%). Comparisons of the demographics between the Hong Kong and Singapore samples indicated that there were considerably more arts and business students in the Hong Kong sample, that there were considerably more engineering/science students in the Singapore sample, and that health care students were included in the Singapore sample but not in the Hong Kong sample.

\section{Statistical Analysis}

CFA in EQS version 6.4 for Windows was used in the analysis. Since preliminary analysis of both samples, whether in aggregate or separate form, showed that the data violated the assumption of multivariate normality shown by Yuan, Lambert, and Fouladi's coefficient, the full information maximum likelihood (FIML) method with robust correction was utilized in the CFA execution, as recommended by Bentler (2006). This correction provided the scaled chi-square (Satorra-Bentler, i.e., $S-B \chi^{2}$ ) and other adjusted indices, which were adopted for assessing the goodness of fit indices for the models.

We used the raw dataset in the CFA analysis, which allowed the test of multivariate normality and adoption of the above correction. For the model specification, a typical CFA parameterization was employed, by loading the 11 developmental domain subscales onto their respective items with free estimation while setting the variance for all developmental domains as 1.0. The covariances between the 11 domains were freely estimated. A constant variable V999 with no variance and a mean value of 1.0 was created for each variable equation to indicate the intercept. For the sake of comparison, no modification, such as error covariance, even if suggested by the Wald and Lagrange multiplier tests, was added to the models.

Besides the model chi-square value, which tends to reject models even if they fit data well (Thompson, 2004), other goodness of fit indices, including CFI, NNFI, and RMSEA, were also used for assessing the models (Tabachnick \& Fidell, 2013). Benchmarks for determining acceptable model fit were adopted as follows: CFI ( $\geq .90)$, NNFI ( $\geq .90)$, and RMSEA $(\leq .10)$ (Bentler, 1990; Brown, 2015; Browne \& Cudeck, 1992). In addition, it was assumed that if CFI and NNFI are .95 or above and RMSEA .06 or less, the model is regarded as satisfactory (Bentler, 2006; Hu \& Bentler, 1999). Moreover, because the adoption of the robust correction in conjunction with the FIML method does not generate standardized root mean square residual (SRMR) values to indicate how well the data fit the model, average absolute standardized residual (AASR) values, which are comparable with SRMR values, were employed (Bentler, 2006). Taking reference from the SRMR-related benchmark, AASR values .08 or less are desirable (Hu \& Bentler, 1999). 


\section{Results}

The CFA results show marginally satisfactory model fit in the aggregate sample $(n=985)$. Although the chisquare was rejected $\left(S-B \chi^{2}=3,097.74, d f=1,429, p=.00\right)$, both NNFI and CFI reached or nearly reached the satisfactory level with values of .94 and .95 , respectively. The RMSEA (.03; CI: .03, .04) and AASR (.03) values were also satisfactory. The standardized factor loadings of the 56 items onto their respective subscales ranged between .72 and .99 , whereas the 11 developmental domains correlated with one another with values between .48 and .93 (see Table 1 for details). In summary, considering the set of goodness of fit indices, as well as the factor loadings and the correlations between the domains, the model was regarded as fitting the aggregate sample well.

A multi-sample analysis was then conducted, in which the Hong Kong and Singapore samples were compared to assess whether the two sets of data shared the same factor structure, as specified in the model used for fitting the aggregate data. The approach recommended by Tabachnick and Fidell (2013) was followed. In the multisample analysis, we started with setting the two samples on the overall factor structure (no constraint condition) invariant, followed by putting constraints on the magnitude of different types of path in the factor structure at each step, namely in sequence, factor loadings, factor covariances, and error covariances, until the significant change of chi-square of goodness of fit indices emerged. To compare whether the result at each step of evaluation was satisfactory, the increment in goodness of fit indices were used, as Cheung and Rensvold (2002) noted that using the traditional likelihood test in terms of the change in chi-square values is likely to yield significant differences. Generally, incremental differences of -.01 or less in goodness of fit indices between the baseline and its subsequent restricted models are considered satisfactory.

Table 2 illustrates the results for multi-sample analysis. The first step of testing both samples on the same

Table 1

The Factor Loadings and Inter-factor Correlations for the Overall Model from the CFA Results

\begin{tabular}{|c|c|c|c|c|c|c|c|c|c|c|c|c|}
\hline \multirow[b]{2}{*}{ Domain } & \multirow[b]{2}{*}{$\begin{array}{l}\text { Factor } \\
\text { loading }\end{array}$} & \multicolumn{11}{|c|}{ Inter-factor correlations } \\
\hline & & KA & CPS & RTS & SRS & CTS & $\mathrm{CCU}$ & $\mathrm{CR}$ & SSR & SE & SU & CSI \\
\hline $\mathrm{KA}$ & $.849-.901$ & 1.00 & & & & & & & & & & \\
\hline CPS & $.724-.873$ & .867 & 1.00 & & & & & & & & & \\
\hline RTS & $.812-.886$ & .794 & .893 & 1.00 & & & & & & & & \\
\hline SRS & $.805-.866$ & .764 & .842 & .789 & 1.00 & & & & & & & \\
\hline CTS & $.839-.862$ & .824 & .911 & .869 & .929 & 1.00 & & & & & & \\
\hline $\mathrm{CCU}$ & $.792-.886$ & .803 & .847 & .822 & .849 & .892 & 1.00 & & & & & \\
\hline $\mathrm{CR}$ & $.855-.992$ & .619 & .617 & .593 & .694 & .700 & .689 & 1.00 & & & & \\
\hline SSR & $.840-.901$ & .616 & .620 & .605 & .678 & .672 & .753 & .868 & 1.00 & & & \\
\hline SE & $.750-.891$ & .722 & .789 & .787 & .685 & .758 & .802 & .484 & .572 & 1.00 & & \\
\hline SU & $.828-.870$ & .757 & .829 & .797 & .751 & .826 & .818 & .642 & .653 & .869 & 1.00 & \\
\hline CSI & $.885-.905$ & .761 & .802 & .762 & .785 & .822 & .843 & .691 & .724 & .804 & .888 & 1.00 \\
\hline
\end{tabular}

Notes. KA: knowledge application; CPS: creative problem-solving skills; RTS: relationship and team skills; SRS: self-reflection skills; CTS: critical thinking skills; CCU: community commitment and understanding: CR: caring and respect; SSR: sense of social responsibility; SE: self-efficacy; SU: self-understanding; CSI: commitment to self-improvement.

All values are statistically significant at the .05 level. 
Table 2

The CFA Results for the Overall Model and the Multi-sample Analysis Between the Hong Kong and Singapore Samples

\begin{tabular}{|c|c|c|c|c|c|c|c|c|c|c|c|c|c|c|c|}
\hline Constraints & $\mathrm{S}-\mathrm{B} \chi^{2^{*}}$ & $d f$ & $p$ & NNFI & CFI & RMSEA & $\begin{array}{l}\text { RMSEA } \\
\text { CI }\end{array}$ & $\Delta \mathrm{S}-\mathrm{B} \chi^{2}$ & $\Delta d f$ & $\Delta p$ & $\triangle \mathrm{NNFI}$ & $\Delta \mathrm{CFI}$ & $\begin{array}{l}\Delta \mathrm{RM}- \\
\mathrm{SEA}\end{array}$ & $\begin{array}{r}\text { Average } \\
\text { stand } \\
\text { res }\end{array}$ & $\begin{array}{l}\text { absolute } \\
\text { rdized } \\
\text { lual }\end{array}$ \\
\hline & & & & & & & & & & & & & & $\mathrm{HK}$ & $\begin{array}{l}\text { Singa- } \\
\text { pore }\end{array}$ \\
\hline Baseline model & $4,485.66$ & 2,858 & .00 & .949 & .952 & .034 & $\begin{array}{l}.032 \\
.036\end{array}$ & $\mathrm{~N} / \mathrm{A}$ & $\mathrm{N} / \mathrm{A}$ & $\mathrm{N} / \mathrm{A}$ & $\mathrm{N} / \mathrm{A}$ & $\mathrm{N} / \mathrm{A}$ & $\mathrm{N} / \mathrm{A}$ & .0211 & .0432 \\
\hline $\begin{array}{l}\text { Factor loadings } \\
\text { equivalent }\end{array}$ & $4,619.79$ & 2,914 & .00 & .947 & .950 & .035 & $\begin{array}{l}.033 \\
.036\end{array}$ & 134.13 & 56 & .00 & -.002 & -.002 & .001 & .0304 & .0549 \\
\hline $\begin{array}{l}\text { Factor coef- } \\
\text { ficients } \\
\text { equivalent }\end{array}$ & $4,820.23$ & 2,969 & .00 & .944 & .946 & .036 & $\begin{array}{l}.034 \\
.037\end{array}$ & 200.49 & 55 & .00 & -.003 & -.004 & .001 & .0523 & .0985 \\
\hline $\begin{array}{l}\text { Factor covari- } \\
\text { ances equivalent }\end{array}$ & $4,896.12$ & 3,025 & .00 & .942 & .944 & .035 & $\begin{array}{l}.034 \\
.037\end{array}$ & 75.85 & 56 & .00 & -.002 & -.002 & -.001 & .0568 & .0964 \\
\hline
\end{tabular}

* S-B $\chi^{2}$ denotes the Satorra-Bentler scaled chi-square values with robust correction applied. The fit indices in the table are also adopting the version of robust correction.

overall factor structure indicated satisfactory results for all the goodness of fit indices (NNFI = .95; CFI = .95; RMSEA = .03; CI: .03, .04; AASR for the Hong Kong sample: .02; AASR for the Singapore sample: .04), despite a significant $S$-B chi-square value $(4,485.66, d f=2,858, p=.00)$. In the second step, we set the factor loadings equal between the same item (variable) and its matching developmental domain (factor) in both samples. Results indicated that all incremental differences of the goodness of fit indices $(\Delta \mathrm{NNFI}=-.002 ; \Delta \mathrm{CFI}=$ -.002; $\triangle \mathrm{RMSEA}=.001$ ) and AASR values (Hong Kong: .03; Singapore: .05) were satisfactory, supporting the equivalence of the factor loadings across the two samples. Although the further restriction of making factor covariances invariant also showed satisfactory results in terms of the incremental differences of the goodness of fit indices $(\triangle \mathrm{NNFI}=-.003 ; \Delta \mathrm{CFI}=-.004 ; \Delta \mathrm{RMSEA}=.001)$, the AASR values for the Singapore sample $(.10)$ indicated the possibility that the data did not fit well in its model, thus rejecting the factor covariance invariant model across the two samples.

The above multi-sample analysis revealed that the model is invariant across the Hong Kong and Singapore samples at the structural level but not for the factor and error covariances. To conclude, the measurement models of the Hong Kong and Singapore samples were considered invariant with the minimum acceptable criterion (Byrne et al., 1989). Table 3 reports the reliability of the 11 developmental domains in terms of Cronbach's alpha value for the two samples, with all domain and overall reliability scores higher than .80 . 
Table 3

Reliability Results in Terms of Cronbach's alpha for the Overall, Hong Kong, and Singapore Samples

\begin{tabular}{lccc}
\hline Domain & Overall & Hong Kong & Singapore \\
\hline KA & .927 & .929 & .914 \\
CPS & .946 & .950 & .938 \\
RTS & .954 & .959 & .944 \\
SRS & .905 & .925 & .869 \\
CTS & .889 & .896 & .871 \\
CCU & .949 & .960 & .928 \\
CR & .963 & .963 & .950 \\
SSR & .898 & .912 & .842 \\
SE & .897 & .925 & .857 \\
SU & .907 & .924 & .866 \\
CSI & .924 & .929 & .911 \\
S-LOMS & .987 & .990 & .979 \\
\hline
\end{tabular}

Notes. KA: knowledge application; CPS: creative problem-solving skills; RTS: relationship and team skills; SRS: self-reflection skills; CTS: critical thinking skills; CCU: community commitment and understanding: CR: caring and respect; SSR: sense of social responsibility; SE: self-efficacy; SU: self-understanding; CSI: commitment to self-improvement.

\section{Study 2}

\section{Methods}

In Study 1, we confirmed that the 11-domain factor structures of the 56-item S-LOMS applied both to the Hong Kong and Singapore samples. In Study 2, we explored any significant differences between the pattern of the pretest and posttest scores obtained from the two samples across the 11 developmental domains of S-LOMS and used historical and cultural analysis to contextualize such differences. The purpose of Study 2 was to illustrate how S-LOMS can serve as a tool for comparing student developmental outcomes under different circumstances-in this case, whether the service-learning took place in Hong Kong or Singapore.

\section{Participants and Procedure}

The Hong Kong sample for Study 2 included the same 655 respondents as in Study 1, who had completed S-LOMS immediately before taking their service-learning course and also completed S-LOMS immediately after completing their service-learning courses. An additional 268 students from HKPU also joined Study 2 by completing 26 items (out of 56) of S-LOMS immediately before and immediately after their service-learning courses. The 26 items completed by the HKPU students comprised all four items from knowledge application, four of the eight items from creative problem-solving skills, four of the eight items from relationship and team skills, all seven items from caring and respect, all three items from sense of social responsibility, and all four items from 
self-understanding. ${ }^{2}$ The responses from the HKPU sub-sample were included in the analysis so as to enrich the sample composition for score comparisons at the domain level.

Consequently, the Hong Kong sample for Study 2 comprised 923 respondents for 26 items and 655 for all items of S-LOMS. This composite sample had a mean age of 20.8 years, with nearly two-thirds of the sample female (65.7\%). In terms of discipline, they came from the arts (27.6\%), social sciences (18.4\%), business (41.1\%), engineering/science (10.2\%), and health care (2.6\%).

The Singapore sample for Study 2 comprised 92 of the 330 students from RP, who in Study 1 had completed S-LOMS before taking their service-learning projects. These 92 students also completed S-LOMS after they had completed their service-learning projects. The mean age of this new sample was 19.1 years, and the sample was mainly female (78.3\%). In terms of discipline, most of the students came from engineering/science (76.1\%), followed by health care $(12.0 \%)$, business $(5.4 \%)$, social sciences $(4.3 \%)$, and the arts $(2.2 \%)$.

\section{Service-Learning Designs}

RP. Introduced in 2007, service-learning programs at RP have been designed and implemented by lecturers from various diploma programs and managed by the Office of Student and Graduate Affairs. All students in the sample had attended an Introduction to Service-Learning workshop as part of their Year 1 Lifeskills module, and they had subsequently elected to join a service-learning program on a voluntarily basis, with service hours depending on each program.

Although RP provides opportunities for students to undertake all four major types of service-learning project-direct, indirect, advocacy, and research-based service-the programs in the current study tended to involve direct service and/or advocacy-based service. Examples included delivering creative arts or engineering workshops to the public and organizing a mental health carnival. The service-learning programs were neither course based nor credit bearing, and there was no formal academic assessment associated with them. Students were nonetheless required to complete assignments, normally in the form of reflective journals and participation in reflective discussions.

Hong Kong Universities. There were a number of broad similarities among the Hong Kong universities in terms of the design and implementation of their service-learning programs. Each university provided opportunities for the four major types of project, as described above, and the Hong Kong sample reflected this range. The service-learning programs were all incorporated into credit-bearing courses. Typically, as means for supporting the field service, pre-service preparatory training, an agency orientation, and consultation sessions were provided. Associated academic assignments typically included a service proposal, a written project report and/or final presentation, and a reflective essay or diary.

There were differences between the Hong Kong universities in terms of the "intensity" of the service-learning experiences. EdUHK, LU, and HKPU stipulated service-learning as a graduation requirement, for which stu-

2. A separate set of CFA and reliability tests were conducted on the scores of the HKPU sample based on the 26-item version of S-LOMS, and these obtained satisfactory results that indicated the same factor structure. 
dents had to fulfill at least 25 (at EdUHK), 30 (at LU), or 40 (at HKPU) course-related service hours. At HSUHK and HKBU, where service-learning was not a graduation requirement, the students in the sample had undertaken a minimum 24 (at HSUHK) or 10 (at HKBU) service hours associated with their service-learning course.

Table 4 compares the service-learning program design between RP and the universities in Hong Kong participating in this study.

\section{Statistical Analysis}

First, a baseline comparison was conducted through independent sample $t$-tests between the pretest scores (the data collected before respondents commenced their service-learning courses or projects) of the Hong Kong and Singapore samples over the 11 developmental domains. Second, paired sample $t$-tests were employed to indicate from the pretest-posttest scores whether there were significant developmental changes arising from servicelearning for the students. Third, independent sample $t$-tests between the Hong Kong and Singapore samples were conducted on their pretest-posttest difference scores to identify whether there were any significant differences in terms of the student developmental outcomes arising from service-learning.

\section{Results}

Descriptive statistics in terms of means and standard deviations of the 11 developmental domains of both the Hong Kong and Singapore samples are reported in columns 2 to 7 and 12 to 17 in Table 5.

The independent sample $t$-tests on the pretest scores for the 11 domains, results of which are given in columns 8 to 11 in Table 5, indicate that the Singapore students scored significantly higher than the Hong Kong students on seven of the 11 development domains. Thus, in terms of pretest scores, the two samples differed statistically significantly on the developmental domains of knowledge application (X Diff $=.54, p=.00$ ), self-reflection skills $(\mathrm{X}$ Diff $=.63, p=.00)$, critical thinking skills (X Diff $=.59, p=.00)$, community commitment and understanding $(\mathrm{X}$ Diff $=.35, p=.00)$, caring and respect $(\mathrm{X}$ Diff $=1.13, p=.00)$, sense of social responsibility $(\mathrm{X}$ Diff $=.98$, $p=.00)$, and commitment to self-improvement (X Diff $=.71, p=.00)$. The mean differences between the pretest scores of the Singapore and Hong Kong students appeared to be especially high on the domains of caring and respect and sense of social responsibility.

Paired sample $t$-test results, comparing the pretest and posttest scores, given in Table 6 , indicated that for all domains the posttest scores for the Hong Kong students were significantly higher than the pretest scores. This fully replicated a previous finding that service-learning experience is associated with improved scores across all 11 S-LOMS domains (e.g., Lau \& Snell, 2020a). Among the Singapore students, posttest scores for eight domains were significantly higher than the pretest scores for those domains. However, pretest-posttest differences were insignificant for the domains of caring and respect $(\Delta X=.00, p=.98)$, sense of social responsibility $(\Delta X=.03$, $p=.77)$, and commitment to self-improvement $(\Delta \mathrm{X}=.20, p=.09)$. Notably, these were the domains for which the Singapore students had indicated their three highest mean pretest scores of 8.81, 8.39, and 7.92, respectively, 
Table 4

Comparison of the Service-Learning Program Design Between RP of Singapore land the Local Universities of Hong Kong in This Study

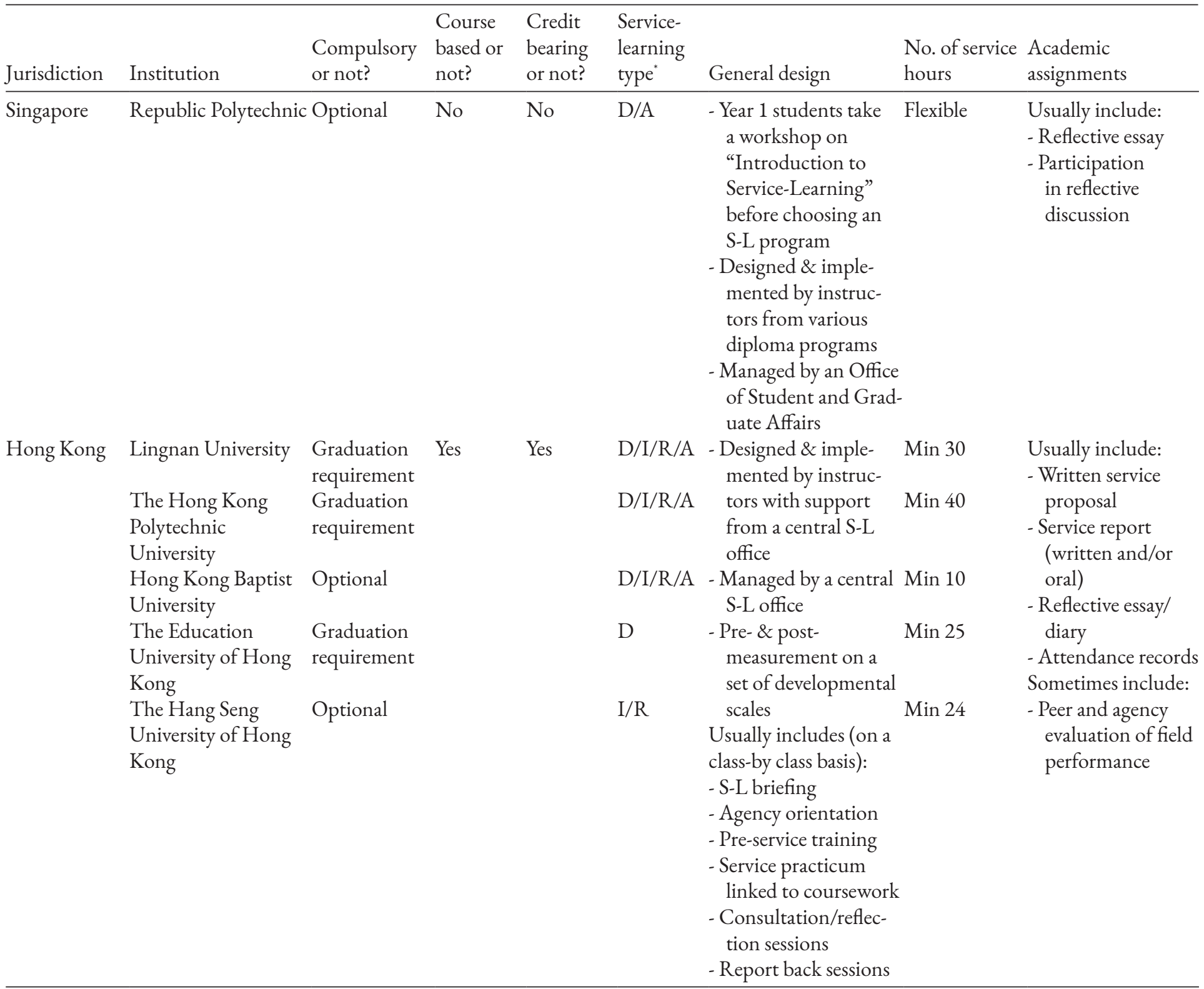

'D: direct service; I: indirect service; R: research service; A: advocacy service.

Sources. Centre for Innovative Service-Learning (2018, n.d.); Centre for Teaching and Learning (n.d.); Learning and Teaching Quality Committee (n.d.); Office of Service-Learning (n.d.); Office of Student and Graduate Affairs of RP (2019); Republic Polytechnic (n.d.); Service-Learning and Leadership Office (n.d.); The Hang Seng University of Hong Kong (2020a, 2020b).

Additional information obtained from The Education University of Hong Kong and Republic Polytechnic, personal communication with authors. 
Table 5

Descriptive Statistics of the Pretest and Posttest Scores and the t-test Results on the Pretest Scores Between the Hong Kong and Singapore Samples

\begin{tabular}{|c|c|c|c|c|c|c|c|c|c|c|c|c|c|c|c|c|}
\hline \multirow[b]{3}{*}{ Domain } & \multicolumn{10}{|c|}{ Pretest } & \multicolumn{6}{|c|}{ Posttest } \\
\hline & \multicolumn{3}{|c|}{ Hong Kong } & \multicolumn{3}{|c|}{ Singapore } & \multicolumn{4}{|c|}{$t$-test comparison } & \multicolumn{3}{|c|}{ Hong Kong } & \multicolumn{3}{|c|}{ Singapore } \\
\hline & $N$ & Mean & s.d. & $N$ & Mean & s.d. & $t$ & $d f$ & $p$ & $\begin{array}{c}\text { Mean } \\
\text { diff }\end{array}$ & $N$ & Mean & s.d. & $N$ & Mean & s.d. \\
\hline $\mathrm{KA}$ & 923 & 6.84 & 1.30 & 92 & 7.39 & 1.17 & -3.85 & 1,103 & .00 & .54 & 923 & 7.47 & 1.38 & 92 & 7.89 & 1.14 \\
\hline CPS & 923 & 6.95 & 1.27 & 92 & 7.20 & 1.30 & -1.77 & 1,103 & .08 & .25 & 923 & 7.57 & 1.28 & 92 & 7.73 & 1.18 \\
\hline RTS & 923 & 6.87 & 1.36 & 92 & 7.14 & 1.35 & -1.86 & 1,103 & .06 & .28 & 923 & 7.56 & 1.29 & 92 & 7.70 & 1.18 \\
\hline SRS & 655 & 7.08 & 1.35 & 92 & 7.70 & 1.33 & -4.18 & 745 & .00 & .63 & 655 & 7.76 & 1.22 & 92 & 8.08 & 1.18 \\
\hline CTS & 655 & 7.00 & 1.33 & 92 & 7.59 & 1.32 & -4.00 & 745 & .00 & .59 & 655 & 7.72 & 1.21 & 92 & 8.00 & 1.04 \\
\hline $\mathrm{CCU}$ & 655 & 6.99 & 1.28 & 92 & 7.33 & 1.13 & -2.46 & 745 & .01 & .35 & 655 & 7.71 & 1.12 & 92 & 8.07 & .93 \\
\hline CR & 923 & 7.68 & 1.33 & 92 & 8.81 & 1.04 & -9.64 & 1,103 & .00 & 1.13 & 923 & 8.10 & 1.19 & 92 & 8.82 & .88 \\
\hline SSR & 923 & 7.41 & 1.37 & 92 & 8.39 & 1.32 & -6.54 & 1,103 & .00 & .98 & 923 & 7.93 & 1.26 & 92 & 8.42 & 1.12 \\
\hline SE & 655 & 6.90 & 1.38 & 92 & 6.79 & 1.73 & .59 & 745 & .56 & -.11 & 655 & 7.64 & 1.25 & 92 & 7.40 & 1.57 \\
\hline SU & 923 & 7.13 & 1.36 & 92 & 7.31 & 1.50 & -1.20 & 1,103 & .23 & .18 & 923 & 7.70 & 1.25 & 92 & 7.84 & 1.40 \\
\hline CSI & 655 & 7.21 & 1.39 & 92 & 7.92 & 1.38 & -4.60 & 745 & .00 & .71 & 655 & 7.73 & 1.21 & 92 & 8.12 & 1.30 \\
\hline
\end{tabular}

Notes. KA: knowledge application; CPS: creative problem-solving skills; RTS: relationship and team skills; SRS: self-reflection skills; CTS: critical thinking skills; CCU: community commitment and understanding: CR: caring and respect; SSR: sense of social responsibility; SE: self-efficacy; SU: self-understanding; CSI: commitment to self-improvement.

Table 6

Paired sample t-test Between the Pretest and Posttest Scores of the Hong Kong and Singapore Samples

\begin{tabular}{|c|c|c|c|c|c|c|c|c|}
\hline \multirow[b]{2}{*}{ Domain } & \multicolumn{4}{|c|}{ Hong Kong } & \multicolumn{4}{|c|}{ Singapore } \\
\hline & Mean diff & $t$ & $d f$ & $p$ & Mean diff & $t$ & $d f$ & $p$ \\
\hline $\mathrm{KA}$ & .63 & 14.42 & 922 & .00 & .51 & 4.77 & 91 & .00 \\
\hline CPS & .62 & 15.05 & 922 & .00 & .53 & 6.93 & 91 & .00 \\
\hline RTS & .70 & 16.56 & 922 & .00 & .56 & 6.01 & 91 & .00 \\
\hline SRS & .68 & 14.25 & 654 & .00 & .37 & 3.86 & 91 & .00 \\
\hline CTS & .72 & 14.98 & 654 & .00 & .41 & 4.55 & 91 & .00 \\
\hline $\mathrm{CCU}$ & .72 & 16.83 & 654 & .00 & .73 & 8.87 & 91 & .00 \\
\hline CR & .42 & 10.25 & 922 & .00 & .00 & .03 & 91 & .98 \\
\hline SSR & .52 & 11.89 & 922 & .00 & .03 & .29 & 91 & .77 \\
\hline SE & .74 & 14.83 & 654 & .00 & .61 & 4.95 & 91 & .00 \\
\hline SU & .56 & 13.16 & 922 & .00 & .52 & 5.31 & 91 & .00 \\
\hline CSI & .52 & 10.97 & 654 & .00 & .20 & 1.71 & 91 & .09 \\
\hline
\end{tabular}

Notes. KA: knowledge application; CPS: creative problem-solving skills; RTS: relationship and team skills; SRS: self-reflection skills; CTS: critical thinking skills; CCU: community commitment and understanding: CR: caring and respect; SSR: sense of social responsibility; SE: self-efficacy; SU: self-understanding; CSI: commitment to self-improvement. 
Table 7

The t-test Results on the Pretest-Posttest Differences Between the

Hong Kong and Singapore Samples

\begin{tabular}{lcccl}
\hline & \multicolumn{4}{c}{ Hong Kong-Singapore } \\
\cline { 2 - 5 } Domain & Mean diff & $t$ & $d f$ & $p$ \\
\hline KA & .12 & 1.04 & 1,103 & .30 \\
CPS & .09 & 1.00 & 1,103 & .32 \\
RTS & .14 & 1.38 & 1,103 & .17 \\
SRS & .31 & 2.85 & 745 & .01 \\
CTS & .31 & 3.02 & 745 & .00 \\
CCU &. .01 & -.12 & 745 & .91 \\
CR & .41 & 3.81 & 1,103 & .00 \\
SSR & .49 & 4.05 & 1,103 & .00 \\
SE & .13 & .89 & 745 & .37 \\
SU & .04 & .36 & 1,103 & .72 \\
CSI & .32 & 2.38 & 745 & .02 \\
\hline
\end{tabular}

Notes. KA: knowledge application; CPS: creative problem-solving skills; RTS: relationship and team skills; SRS: self-reflection skills; CTS: critical thinking skills; CCU: community commitment and understanding: CR: caring and respect; SSR: sense of social responsibility; SE: selfefficacy; SU: self-understanding; CSI: commitment to self-improvement.

suggesting the possibility that a "ceiling effect" may have limited the room for further development on those domains, as gauged by changes on the 10-point Likert scale adopted in S-LOMS.

Independent sample $t$-tests between the pretest-posttest difference scores of the Hong Kong and Singapore samples (given in Table 7) indicated that the developmental gains arising from service-learning were significantly greater for Hong Kong students than for Singapore students on these three domains, namely caring and respect $(\mathrm{X}$ Diff $=.41, p=.00)$, for sense of social responsibility $(\mathrm{X}$ Diff $=.49, p=.00)$, and for commitment to selfimprovement $(\mathrm{X}$ Diff $=.32, p=.02)$.

Among the other eight domains, there were also significantly greater developmental gains for the Hong Kong students in the two domains of self-reflection skills ( X Diff $=.31, p=.01$ ) and critical thinking skills ( $X$ Diff $=$ $.31, p=.00)$. These two domains were those for which the Singapore students had indicated their fourth and fifth highest mean pretest scores (after caring and respect, sense of social responsibility, and commitment to self-improvement).

Thus, we observed a significantly smaller magnitude of developmental gains arising from service-learning for Singapore students than for Hong Kong students on five domains. Notwithstanding these differences, we still consider that the significant improvements observed for the Singapore sample on eight domains, along with a sign of improvement on a ninth domain, that is, commitment to self-improvement, constitute broad confirmation that S-LOMS is salient for and applicable to the measurement of developmental outcomes through servicelearning in Singapore. 


\section{Discussion}

The current research examined the validity of S-LOMS when used with a sample of Singapore-based tertiary education students and compared the pretest and posttest scores of Hong Kong- and Singapore-based samples. Through CFA, Study 1 confirmed the validity of S-LOMS in terms of the factor structure, along with the resilience of the 11 constituent developmental domains across the Hong Kong and Singapore samples, as shown by the model invariance established in the multi-sample analysis. These findings are consistent with our identification of broad similarities in service-learning policies, purposes, and designs in Hong Kong and Singapore, in turn reflecting broad similarities in civic education policies in the two jurisdictions.

Study 2 established from pretest and posttest scores that the Hong Kong sample significantly improved on all 11 developmental domains, whereas the Singapore sample significantly improved on eight domains. Three main patterns of scores were found in Study 2 when comparing Hong Kong and Singapore students across the 11 developmental domains.

\section{Higher Pretest Scores of Singapore Students}

One pattern was that the pretest scores of the Singapore students were significantly higher than those of the Hong Kong students on seven of the developmental domains, whereas the pretest scores of the Hong Kong students were significantly higher than those of the Singapore students on none of the developmental domains. There are several possible explanations for the significant differences in pretest scores between the students in the two jurisdictions.

First, the higher pretest scores for Singapore students may reflect differences between Hong Kong and Singapore in terms of the relative amounts of community service required for pre-tertiary students. As discussed earlier, Singapore has required students from primary and secondary schools to fulfill quotas for various kinds of community service, through the CIP program and later the VIA program, which have been structured and implemented by the MOE as part of their civic education policies. Even at the pre-school level, the Singapore government has stipulated a set of desired attributes to be fostered, namely, being willing to share and take turns with others; being able to relate to others; being able to listen and speak with understanding; and loving their families, friends, and teachers (Tan, 2007). In contrast, despite espousing the importance of civic education and advocating the adoption of service-learning in primary and secondary schools, authorities in Hong Kong have been criticized for having adopted a merely symbolic policy. According to the criticisms, the Hong Kong authorities had neglected to act on this matter prior to the transfer of sovereignty in 1997, and they had been unable to implement coherent policies in the post-transition era. The post-1997 inertia may reflect impasses between the HKSAR government, which has advocated that civic education should instill patriotism, nationalism, and Chinese cultural identity, and opinion leaders in wider society, who have called for civic education to emphasize critical thinking and democratic values (Morris \& Scott, 2003), or a more Western model of civic education. Without broad consensus, relatively little has been done at the governmental level to promote the 
moral and civic education of pre-tertiary students in Hong Kong, apart from leaving the implementation of service-learning to the discretion of schoolteachers.

Second, higher pretest scores among Singapore students may reflect differences between the two jurisdictions in terms of the intensity and substance of attempts by their respective governments to promote lifelong learning. The Singapore government led the Thinking Schools, Learning Nation initiative (Kumar, 2004) to encourage citizens and students to engage in lifelong learning (Lee \& Morris, 2016), followed by the SkillsFuture movement, introduced in 2014 (Tan, 2017; Yorozu, 2017). By comparison, although the Hong Kong government has also espoused the need for lifelong learning, it has lagged behind Singapore and even Malaysia in terms of practical application (Cribbin, 2010). That the Singapore students had already been oriented during their primary and secondary education to value community service and lifelong learning may accordingly have contributed to their relatively higher pretest scores vis-à-vis the Hong Kong students.

A third possible explanation may concern the institutions at which the samples were obtained. The Hong Kong students came from traditional local universities, whereas all the Singapore students came from a single polytechnic institution, which focuses more sharply on vocational skills training. Moreover, disciplinary-based differences may also have affected our results: nearly three-quarters of the students in the Hong Kong sample were from the arts or business, whereas in the Singapore sample, more than $80 \%$ were from engineering/science or health care. Furthermore, the students in RP had chosen service-learning voluntarily, unlike those in Hong Kong, who had to participate to fulfill institutional requirements.

\section{Differences in Developmental Gains}

The second pattern of results was that whereas the Hong Kong students reported significant improvements after service-learning on all 11 domains, the Singapore students reported significant improvements on only eight of the domains and did not report significant improvements for three domains, namely, caring and respect, sense of social responsibility, and commitment to self-improvement.

A possible explanation for this second pattern of results is that there was a "ceiling effect" (Salkind, 2010) on three domains for Singapore students, indicating that their pretest scores had already reached the maximum range in the pretest. This pattern may reflect that their pre-tertiary community service exposure had left relatively little leeway for further enhancement in those domains.

The third pattern of results indicated that, as compared with the Singapore students, the pretest-posttest difference in scores of the Hong Kong students were generally higher across the 11 developmental domains, and these were significantly higher on the five domains of caring and respect, sense of social responsibility, commitment to self-improvement, self-reflection skills, and critical thinking skills. Setting aside those developmental domains, namely, caring and respect, sense of social responsibility, and commitment to self-improvement, which may have been affected by ceiling effects, measurements on the eight remaining developmental domains indicated that the Hong Kong students may have perceived themselves as having greater enhancement on those domains than their Singaporean counterparts. 
A possible explanation for the third pattern of results may lie in differences between the two samples in terms of service-learning program design. As described earlier, the RP service-learning programs were implemented independently of any credit-bearing course, and they did not require academic assessment of related reflectionbased assignments. By contrast, the service-learning programs undertaken by students in the Hong Kong sample were embedded in credit-bearing courses, which some universities even stipulated as a graduation requirement. Moreover, the service-learning projects for the Hong Kong students were designed systematically with formally stipulated minimum service hours and were combined with a series of required assignments, including project proposals, oral presentations and/or written reports, and reflective journals. Furthermore, the related academic assignments for Hong Kong students were closely related to the respective course grading systems. Given these requirements, we consider that the design of the service-learning programs undertaken by the Hong Kong sample may have contributed to their greater enhancement within the developmental domains measured by S-LOMS, in comparison with the Singapore sample.

\section{Conclusions and Recommendations}

The current study began the process of examining the applicability of S-LOMS in other jurisdictions in Asia besides Hong Kong, with Singapore selected as the first comparison, given their similar educational philosophies and policies in relation to service-learning. The discovery of an invariant factor structure for S-LOMS across samples from Hong Kong and Singapore has established the instrument's validity beyond Hong Kong and has paved the way for its validation and application elsewhere in Asia.

If S-LOMS, as a standardized measurement tool, were to be validated across Asia, research on service-learning across the continent could potentially benefit from the opportunity for more systematic comparisons across jurisdictions, educational institutions, and service-learning programs. In that event, the creation of a database of accumulated student developmental outcomes across the 11 developmental domains would become possible, paving the way for big data analysis in the future. Because of its reliable factor structure, S-LOMS offers flexibility in administration, such that investigators can tailor make a shortened version of S-LOMS, such as the 26-item version adopted by HKPU, targeting the developmental domains that are of most interest to them.

However, the current study also indicated the possibility that S-LOMS may encounter ceiling effects as the use of the scale is extended to new jurisdictions beyond Hong Kong, where the coordinates of new subsets of respondents on the spectrum of the subscales remain unknown until measured. Accordingly, we recommend the approach adopted by Salkind (2010), of using S-LOMS in conjunction with other assessment tools in order to ascertain true values. Other possible steps for reducing ceiling effects include modifying the number of response options for the purpose of capturing high values, adding anchor labels against the rating scales as a means for managing respondents' expectations, or changing the response format by asking respondents in the posttest about their perceptions of the extent of enhancement on each item as compared with when they took the pretest.

A substantive discovery arising from the current study was the pattern of consistently higher perceived pretestposttest enhancement arising from service-learning for the Hong Kong students as compared with the Singapore 
students. Although this pattern may partly reflect the different backgrounds of the two samples of respondents, we consider that it can also be attributed to differences between the two jurisdictions in terms of the design of the service-learning programs undertaken by the two samples of students. Past research findings indicate that more systematically designed service-learning programs - in terms of standardized service-hours, alignment of service with course content, and integration of service with grading and assessment requirements-yield superior developmental outcomes for students (e.g., Astin et al., 2000; Mabry, 1998). We therefore recommended that RP and other educational institutions with similar service-learning arrangements can consider forging closer ties between their service-learning programs and regular academic courses (e.g., Hanover Research, 2014; Jenkins \& Sheehey, 2012; Snell \& Lau, 2020).

\section{Limitations and Further Research}

The current study, as an exploratory investigation, is subject to a number of limitations. First, it is possible that the Hong Kong and Singapore students were different in terms of their academic level, as the former were all from universities, whereas the latter came from a polytechnic institution. Any such difference might have been a factor behind the score discrepancies revealed in Study 2. Further studies could seek to replicate the findings of the current study with samples from other types of higher education institution in Singapore to enhance sample comparability.

Second, a higher level of differentiation of the respondents' backgrounds should be obtained in data collection from a larger sample. In particular, the small sample size ( $n=92$ for Study 2$)$ of the Singapore sample in the current study limits its generalizability. We recommend further studies with a larger sample of students from diverse Singaporean ethnic backgrounds. For example, the Singapore sample took no account of the students' ethnic background, which may be important, as the Malays in Singapore may have insufficient access to university education and hence high-end occupations, yet they make up 15\% of the Singapore population (Department of Statistics, Singapore, 2020). Students' ethnic background may be an important factor affecting developmental outcomes from service-learning, and this should be accounted for in further research studies in Asia.

Apart from ethnicity, the extent to which students had previously engaged in community service might have also influenced their service-learning experience and developmental outcomes in the current study. Future research should seek to collect such data. Another possible confounding variable was student major, given that most Hong Kong students were from the arts and business, whereas the Singapore students were mainly from engineering, science, or health care disciplines. If possible, future cross-jurisdictional comparative research should seek to match the samples more closely according to student major.

Third, there were some differences between the Hong Kong and Singapore samples in terms of servicelearning policies and designs. For example, Hong Kong students were required to complete service-learning to fulfill university requirements, whereas their Singapore counterparts participated in service-learning on their own volition. There were differences between institutions in terms of service-learning designs and structures (as shown in Table 4). These factors could not be controlled in the current study. 
Fourth, Study 2 indicated that the differences in pretest and posttest scores were significantly greater for the Hong Kong sample than for the Singapore sample on a number of domains. Although we have offered possible explanations for the observed differences, the current study could not empirically establish the reasons for this, given that many unmeasured factors may have affected the developmental outcomes for students (e.g., the pedagogical design of the service-learning project experiences). Moreover, although we have argued that Singapore and Hong Kong share many similarities in societal contexts, educational policies, civic education, and servicelearning goals, understanding how these and other factors, such as political systems, affect the implementation and developmental impacts of service-learning would require further studies.

Alternatively, or in addition, future studies could employ S-LOMS in conjunction with other relevant measurement tools, such as the Common Outcomes Measurement (Ma et al., 2019) or the Service Learning Benefit (SELEB) scale (Toncar et al., 2006). Lastly, building on this exploratory comparative study, future research can involve representatives from alternative or additional jurisdictions.

\section{References}

Astin, A. W., Vogelgesang, L. J., Ikeda, E. K., \& Yee, J. A. (2000). How service learning affects students. University of California, Los Angeles, Higher Education Research Institute.

Bell, D. A. (1995). A communitarian critique of authoritarianism. Society, 32(5), 38-43.

Bentler, P. M. (1990). Comparative fit indexes in structural models. Psychological Bulletin, 107(2), 238-246.

Bentler, P. M. (2006). EQS 6 structural equations program manual. Multivariate Software, Inc.

Brown, T. A. (2015). Confirmatory factor analysis for applied research (2nd ed.). Guilford Press.

Browne, M. W., \& Cudeck, R. (1992). Alternative ways of assessing model fit. Sociological Methods and Research, 21(2), 230-258.

Byrne, B. M., Shavelson, R. J., \& Muthén, B. (1989). Testing for the equivalence of factor covariance and mean structures: The issue of partial measurement invariance. Psychological Bulletin, 105(3), 456-466.

Census and Statistics Department of the HKSAR Government. (2020). Population by ethnicity and year. https://www.bycensus2016.gov.hk/en/bc-mt.html?search=A104

Centre for Innovative Service-Learning. (2018). Service-learning manual: For course instructors. Hong Kong Baptist University. https://cisl.hkbu.edu.hk/f/publication/1797/SL\%20Manual_Final\%20\%28Full\%29.pdf

Centre for Innovative Service-Learning. (n.d.). Definition and general guidelines for credit-bearing courses with service-learning components. Hong Kong Baptist University. Retrieved August 26, 2021, from https://cisl. hkbu.edu.hk/about-cisl/SL-definition.

Centre for Teaching and Learning. (n.d.). Guidelines and support. The Hang Seng University of Hong Kong. Retrieved August 26, 2021, from https://service-learning.hsu.edu.hk/staff/framework-of-service-learning/.

Chang, C., \& Yap, M. S. (2017). Service-learning: Appreciating the community as co-educator. In T. Y. Leong \& H. M. Cheah (Eds.), The heart of learning (pp. 171-182). Singapore University of Social Sciences.

Cheng, C.-Y. (2004). A theory of Confucian selfhood: Self-cultivation and free will in Confucian philosophy. In 
K.-L. Shun \& D. B. Wong (Eds.), Confucian ethics: A comparative study of self, autonomy, and community (pp. 124-147). Cambridge University Press.

Cheung, A. B. L. (2007). Executive-led governance or executive power "hollowed-out" - The political quagmire of Hong Kong. Asian Journal of Political Science, 15(1), 17-38.

Cheung, G. W., \& Rensvold, R. B. (2002). Evaluating goodness-of-fit indexes for testing measurement invariance. Structural Equation Modeling, 9(2), 233-255.

Choo, J., Tan, Y. K., Ong, F., Tiong, S. S., Nair, S., Ong, J., \& Chan, A. (2019). What works in service-learning? Achieving civic outcomes, academic connection, career preparation, and personal growth in students at Ngee Ann Polytechnic. Michigan Journal of Community Service Learning, 25(2), 95-132. https://doi.org/10.3998/ mjcsloa.3239521.0025.208

Cribbin, J. (2010). The lifelong learning sector and the development of Hong Kong as a regional education hub: Is government policy rhetoric or reality? International Education Studies, 3(4), 46-58.

Curriculum Development Council. (2001). Learning to learn: Life-long learning and whole-person development. Curriculum Development Council. https://www.edb.gov.hk/en/curriculum-development/cs-curriculum-doc-report/wf-in-cur/index.html

Department of Statistics, Singapore. (2020). Singapore citizens by age group, ethnic group and sex, end June, annual. https://www.tablebuilder.singstat.gov.sg/publicfacing/createDataTable.action? refId=15689

Education Bureau of the HKSAR Government. (2020). Service learning. https://www.edb.gov.hk/tc/curriculum-development/4-key-tasks/moral-civic/Newwebsite/flash/servicelearning/service.html\#4

Eyler, J., \& Giles, D. E., Jr. (1999). Where's the learning in service-learning? Jossey-Bass.

Gabrenya, W. K., Jr., \& Hwang, K.-K. (1996). Chinese social interaction: Harmony and hierarchy on the good earth (pp. 309-321). In M. H. Bond (Ed.), The handbook of Chinese psychology (pp. 309-321). Oxford University Press.

George, C. (2007). Consolidating authoritarian rule: Calibrated coercion in Singapore. The Pacific Review, 20(2), 127-145. https://doi.org/10.1080/09512740701306782

Gopinathan, S. (2007). Globalisation, the Singapore developmental state and education policy: A thesis revisited. Globalisation, Societies and Education, 5(1), 53-70. https://doi.org/10.1080/14767720601133405

Hanover Research. (2014). Best practices for scaling service-learning. Hanover Research.

HistorySG. (2020). Launch of community involvement programme (1st Oct 1997). https://eresources.nlb.gov.sg/ history/events/c78526c6-decf-4b79-b4ca-421739464884

Hofstede, G. (1983). Dimensions of national cultures in fifty countries and three regions. In J. B. Deregowski, S. Dziurawiec, \& R. C. Annis (Eds.), Expiscations in cross-cultural psychology (pp. 335-355). Swets and Zeitlinger.

Hu, L., \& Bentler, P. M. (1999). Cutoff criteria for fit indexes in covariance structure analysis: Conventional criteria versus new alternatives. Structural Equation Modeling, 6(1), 1-55.

Jacoby, B. (1996). Service-learning in higher education: Concepts and practices. Jossey-Bass.

Jenkins, A., \& Sheehey, P. (2012). A checklist for implementing service-learning in higher education. Journal of Community Engagement and Scholarship, 4(2). http://jces.ua.edu/a-checklist-for-implementing-service-learning-in-higher-education/ 
Kumar, P. (2004). Lifelong learning in Singapore: Where are we now? International Journal of Lifelong Education, 23(6), 559-568. https://doi.org/10.1080/026037042000311479

Lau, K. H., Chan, M. Y. L., Yeung, C. L. S., \& Snell, R. S. (in press). An exploratory study of the community impacts of service-learning. Metropolitan Universities.

Lau, K. H., \& Snell, R. S. (2020a). Assessment of developmental outcomes of students arising from service-learning [Manuscript submitted for publication].

Lau, K. H., \& Snell, R. S. (2020b). Service-learning outcomes measurement scale (S-LOMS): The user manual. Office of Service-Learning, Lingnan University. https://doi.org/10.14793/9789887522201

Lau, K. H., \& Snell, R. S. (2020c). Test-retest reliability and validity of the service-learning outcomes measurement scale. International Journal of Research on Service-Learning and Community Engagement, 8(1), Article 7. https://doi.org/10.37333/001c.18782

Lau, K. H., \& Snell, R. S. (2021). Confirmatory factor analysis for a Service-Learning Outcomes Measurement Scale (S-LOMS). Metropolitan Universities, 32(1), 3-34. https://doi.org/10.18060/23920

Lee, M., \& Morris, P. (2016). Lifelong learning, income inequality and social mobility in Singapore. International Journal of Lifelong Education, 35(3), 286-312.

Lee, M. H., \& Gopinathan, S. (2018). Fostering economic competitiveness, national identity and social equity through education reforms: The cases of Singapore and Hong Kong. In J. Zajda (Ed.), Globalisation and education reforms: Vol. 19. Globalisation, comparative education and policy research (pp. 181-203). Springer. https://doi.org/10.1007/978-94-024-1204-8_11

Learning and Teaching Quality Committee. (n.d.). Co-curricular and service learning. The Education University of Hong Kong. Retrieved August 26, 2021, from https://lt.eduhk.hk/student-learning/ co-curricular-and-service-learning/.

Leung, Y. W., \& Ng, H. Y. (2014). Delivering civic education in Hong Kong: Why is it not an independent subject? Citizenship, Social and Economics Education, 13(1), 2-13. https://doi.org/10.2304/csee.2014.13.1.2

Ma, C. (2018a, March 19). Community engagement and service-learning in Asia [Paper presentation]. Brown Bag Series at Providence University, Providence: Rhode Island, USA.

Ma, C. (2018b). Service-learning development in higher education in Hong Kong. In T. W. Lim \& T. Y. Kong (Eds.), Studying Hong Kong: 20 years of political, economic and social developments (pp. 43-61). World Scientific. https://doi.org/10.1142/9789813223554_0004

Ma, H. K. C., Chan, C. W. F., \& Tse, P. H. I. (2019). A common outcome measurement for service-learning in Hong Kong. Journal of Higher Education Outreach and Engagement, 23(3), 3-19.

Mabry, J. B. (1998). Pedagogical variations in service-learning and student outcomes: How time, contact, and reflection matter. Michigan Journal of Community Service Learning, 5, 32-47.

Marginson, S. (2011). Higher education in East Asia and Singapore: Rise of the Confucian model. Higher Education, 61, 587-611. https://doi.org/10.1007/s10734-010-9384-9

Ministry of Education (MOE) of Singapore. (2020). Values in action. https://www.moe.gov.sg/programmes/ values-in-action 
Morris, P., \& Adamson, B. (2010). Curriculum, schooling and society in Hong Kong. Hong Kong University Press.

Morris, P., \& Scott, I. (2003). Educational reform and policy implementation in Hong Kong. Journal of Education Policy, 18(1), 71-84.

Office of Service-Learning. (n.d.). Service-learning graduation requirement. Lingnan University. Retrieved August 26, 2021, from https://www.ln.edu.hk/osl/home/service-learning-graduation-requirement.

Office of Student and Graduate Affairs of RP. (2019). Research proposal for service learning at Republic Polytechnic [Unpublished manuscript].

Republic Polytechnic. (n.d.). Service-learning. Republic Polytechnic. Retrieved August 26, 2021, from https:// www.rp.edu.sg/beyond-classroom

Salkind, N. J. (2010). Ceiling effect. In Encyclopedia of research design (Vol. 1, pp. 133-134). SAGE. https://doi. org/10.4135/9781412961288.n44

Service-Learning and Leadership Office. (n.d.). Policies $\Xi^{2}$ guidelines. The Hong Kong Polytechnic University. Retrieved August 26, 2021, from https://www.polyu.edu.hk/osl/index. php?option $=$ com_content $\&$ view $=$ article $\&$ id $=89 \&$ Itemid $=104 \#$ policies 01

Shek, D. T. L., \& Chan, S. C. F. (2013). Service-learning from the views of university teachers: A qualitative study based on focus groups. International Journal of Adolescent Medicine and Health, 25(4), 385-393. https://10.1515/ijamh-2013-0036

Shek, D. T. L., Yu, L., Wu, F. K. Y., \& Chai, W. Y. (2015). General university requirements at Hong Kong Polytechnic University: Evaluation findings based on student focus groups. Assessment E Evaluation in Higher Education, 40(8), 1017-1031. https://doi.org/10.1080/02602938.2014.960362

Shumer, R., Stanton, T. K., \& Giles, D. E., Jr. (2017). History and precursors of service-learning theory, development, and research. In R. Shumer (Ed.), Where's the wisdom in service-learning? (pp. 1-32). Information Age Publishing.

Sim, J. B.-Y., \& Print, M. (2005). Citizenship education and social studies in Singapore: A national agenda. International Journal of Citizenship and Teacher Education, 1(1), 58-73.

Snell, R. S., Chan, M. Y.-L., Wu, C. X., \& Chan, C. W.-Y. (2019). Service leadership emergence through servicelearning internships in Hong Kong. Michigan Journal of Community Service Learning, 25(2), 167-199. https://doi.org/10.3998/mjcsloa.3239521.0025.211

Snell, R. S., \& Lau, K. H. (2020). The development of a Service-Learning Outcomes Measurement Scale (S-LOMS). Metropolitan Universities, 31(1), 44-77. https://doi.org/10.18060/23258

Tabachnick, B. G., \& Fidell, L. S. (2013). Using multivariate statistics (6th ed.). Allyn \& Bacon.

Tan, C. (2017). Lifelong learning through the SkillsFuture movement in Singapore: Challenges and prospects. International Journal of Lifelong Education, 36(3), 278-291. https://doi.org/10.1080/02601370.2016.1241 833

Tan, C. T. (2007). Policy developments in pre-school education in Singapore: A focus on the key reforms of kindergarten education. International Journal of Child Care and Education Policy, 1(1), 35-43. 
Tan, K. (2009). Service learning outside the U.S.: Initial experiences in Singapore's higher education. PS: Political Science E̊ Politics, 42(3), 549-557. https://doi.org/10.1017/S104909650909088X

The Hang Seng University of Hong Kong. (2020a). Service-learning toolkit for module instructors. ServiceLearning Section, Centre for Teaching and Learning, The Hang Seng University of Hong Kong.

The Hang Seng University of Hong Kong. (2020b). Service-learning toolkit for students. Service-Learning Section, Centre for Teaching and Learning, The Hang Seng University of Hong Kong.

Thompson, B. (2004). Exploratory and confirmatory factor analysis: Understanding concepts and applications. American Psychological Association.

Toncar, M. F., Reid, J. S., Burns, D. J., Anderson, C. E., \& Nguyen, H. P. (2006). Uniform assessment of the benefits of service learning: The development, evaluation, and implementation of the Seleb scale. Journal of Marketing Theory and Practice, 14(3), 223-238.

Tu, W.-M. (1971). The neo-Confucian concept of man. Philosophy East and West, 21(1), 79-87.

Tu, W.-M. (1996). Confucian traditions in East Asian modernity. Bulletin of the American Academy of Arts and Sciences, 50(2), 12-39. https://doi.org/10.2307/3824246

Turner, B. S. (2014). Soft authoritarianism, social diversity and legal pluralism: The case of Singapore. In A. Possamai, J. T. Richardson, \& B. S. Turner (Eds.), The sociology of Sharia: Case studies from around the world (pp. 69-81). Springer. https://doi.org/10.1007/978-3-319-09605-6_5

Wong, M. M. L., Lau, K. H., \& Chan, C. W. F. (2021). The impacts and success factors of a work-from-home service-learning internship during COVID-19. Journal of Work-Applied Management. Advance online publication. https://doi.org/10.1108/JWAM-01-2021-0003

Wong, S. T. (1988). Singapore's new education system: Education reform for national development. Institute of Southeast Asian Studies.

Woo, J. J. (Ed.). (2019). Educating for empathy: Service learning in public policy education. World Scientific Publishing.

Xing, J., \& Ma, C. (2010). Service-learning in Asia: Curricular models and practices. Hong Kong University Press. https://doi.org/10.5790/hongkong/9789888028467.001.0001

Yorozu, R. (Ed.). (2017). Lifelong learning in transformation: Promising practices in Southeast Asia. UNESCO Institute for Lifelong Learning.

\section{Author Note}

This article results from a cross-institutional project named Cross-Institutional Capacity Building for ServiceLearning in Hong Kong Higher Education Institutions (PolyU4/T\&L/16-19), aimed at enhancing and supporting the development of service-learning as an effective pedagogical strategy under the collaboration of The Hong Kong Polytechnic University, Lingnan University, Hong Kong Baptist University, and The Education University of Hong Kong. The project was launched in 2017 and has been funded by the University Grants Committee (UGC) of the Hong Kong Special Administrative Region (HKSAR) government. The authors wish 
to thank the UGC for funding the project and the above institutions for their participation in the process of scale development and validation. Moreover, the authors would like to especially extend our gratitude to the Office of Student and Graduate Affairs of Republic Polytechnic for their assistance in collecting the data for the Singapore sample.

The first author is currently with the Service-Learning and Leadership Office of The Hong Kong Polytechnic University.

\section{Author Bios}

Ka Hing LAU, currently a Project Associate in the Service-Learning and Leadership Office of The Hong Kong Polytechnic University, was a Senior Project Officer in the Office of Service-Learning of Lingnan University. He has a MPhil in Psychology and has years of experience conducting both academic and business research. His current research interests include developing measurement instruments for assessing impacts arising from service-learning, faculty engagement in service-learning, e-service-learning, training and development, and work-from-home.

Robin Stanley SNELL is currently a Visiting Professor in the Department of Management at The Hang Seng University of Hong Kong. Before retiring from Lingnan University, he had served there as Head of the Management Department, Director of Business Programmes, Director of Teaching and Learning, and Director of Service-Learning. His research and teaching interests include service-learning, managerial and organizational learning, leadership and strategic management, and business ethics. 


\section{APPENDIX}

The S-LOMS Categories, Domains, and Items

\begin{tabular}{|c|c|c|}
\hline $\begin{array}{l}\text { Item no. } \\
\text { in scale }\end{array}$ & Domain & Item \\
\hline \multicolumn{3}{|c|}{ Category: Knowledge Application } \\
\hline 01 & Knowledge application & $\begin{array}{l}\text { I know how to transfer knowledge and skills from one } \\
\text { setting to another. }\end{array}$ \\
\hline 02 & Knowledge application & I can make connections between theory and practice. \\
\hline 03 & Knowledge application & $\begin{array}{l}\text { I am able to apply/integrate classroom knowledge to deal } \\
\text { with complex issues. }\end{array}$ \\
\hline 04 & Knowledge application & $\begin{array}{l}\text { I know how to apply what I learn in class to solve real-life } \\
\text { problems. }\end{array}$ \\
\hline \multicolumn{3}{|c|}{ Category: Personal and Professional Skills } \\
\hline 05 & Relationship and team skills & I am good at building relationships between people. \\
\hline 06 & Relationship and team skills & I can easily establish effective relationships with people. \\
\hline 07 & Relationship and team skills & I can build long-term relationships with people. \\
\hline 08 & Relationship and team skills & I am good at keeping in touch with people. \\
\hline 09 & Relationship and team skills & $\begin{array}{l}\text { I have the necessary skills for making groups or organizations } \\
\text { function effectively. }\end{array}$ \\
\hline 10 & Relationship and team skills & I am good at resolving conflicts. \\
\hline 11 & Relationship and team skills & I am confident in leading others toward common goals. \\
\hline 12 & Relationship and team skills & I participate effectively in group discussions and activities. \\
\hline 13 & Creative problem-solving skills & I am able to solve challenging real-life problems. \\
\hline 14 & Creative problem-solving skills & I feel confident in dealing with a problem. \\
\hline 15 & Creative problem-solving skills & $\begin{array}{l}\text { I often modify my strategies to solve a problem when the } \\
\text { situation changes. }\end{array}$ \\
\hline 16 & Creative problem-solving skills & I feel confident in identifying the core of a problem. \\
\hline 17 & Creative problem-solving skills & I am not afraid of trying new things. \\
\hline 18 & Creative problem-solving skills & I am able to generate original ideas. \\
\hline 19 & Creative problem-solving skills & I am able to look at an issue from a fresh perspective. \\
\hline 20 & Creative problem-solving skills & When necessary, I can think of alternatives. \\
\hline 21 & Self-reflection & I always think how I can improve myself. \\
\hline 22 & Self-reflection & I will evaluate myself after completing a task. \\
\hline 23 & Self-reflection & $\begin{array}{l}\text { I consider circumstances when reflecting on how well I have } \\
\text { performed. }\end{array}$ \\
\hline 24 & Self-reflection & I reflect on myself regularly. \\
\hline 25 & Critical thinking skills & I can analyze an issue comprehensively. \\
\hline 26 & Critical thinking skills & I often look at complex issues from different angles. \\
\hline 27 & Critical thinking skills & $\begin{array}{l}\text { I can understand others' viewpoints when we are making } \\
\text { decisions together. }\end{array}$ \\
\hline
\end{tabular}

Category: Civic Orientation and Engagement

28 Community commitment and understanding

29 Community commitment and understanding

30 Community commitment and understanding

31 Community commitment and understanding

32 Community commitment and understanding

33 Community commitment and understanding
I think about how I can serve the community after graduating.

I will play my part to reduce social problems.

I always actively discuss possible improvements for our community.

I will contribute my abilities to make the community a better place.

I can identify challenges in the community.

I can investigate the challenges faced by people in need in a community. 
34 Community commitment and understanding

35 Community commitment and understanding

$36 \quad$ Caring and respect

$37 \quad$ Caring and respect

$38 \quad$ Caring and respect

39 Caring and respect

$40 \quad$ Caring and respect

$41 \quad$ Caring and respect

$42 \quad$ Caring and respect

43 Sense of social responsibility

$44 \quad$ Sense of social responsibility

45 Sense of social responsibility
I can identify issues that are important for a disadvantaged community.

I can identify useful resources of a community.

I can respect people whose background is different from mine.

I am willing to try to understand people whose background is different from mine.

I respect the needs of people from different backgrounds.

I appreciate the ideas of people from different backgrounds.

I observe others' feelings and emotions.

I consider others' points of view.

I care about others.

I believe that taking care of people who are in need is everyone's responsibility.

I feel obligated to help those who are less fortunate than me.

I believe that everybody should be encouraged to participate in civic affairs.

Category: Self-awareness

\begin{tabular}{lll}
\hline 46 & Self-efficacy & Most things I do, I do well. \\
47 & Self-efficacy & I have many good qualities. \\
48 & Self-efficacy & I am satisfied with my achievement so far. \\
49 & Self-efficacy & I am positive about myself. \\
50 & Self-understanding & I have a clear picture of what I am like as a person. \\
51 & Self-understanding & I know my strengths and weaknesses. \\
52 & Self-understanding & I have a clear understanding of my own values and \\
& & principles. \\
53 & Self-understanding & I know what I need in my life. \\
54 & Commitment to self-improvement & I am always motivated to learn. \\
55 & Commitment to self-improvement & I always keep my knowledge and skills up to date. \\
56 & Commitment to self-improvement & I look out for new skills or knowledge to acquire. \\
\hline
\end{tabular}

